\title{
Magnetic Material Assessment of a Novel Ultra-High Step-Up Converter with Single Semiconductor Switch and Galvanic Isolation for Fuel-Cell Power System
}

\author{
Chih-Lung Shen * and Heng Liou \\ Department of Electronic Engineering, National Kaohsiung First University of Science and Technology, \\ Kaohsiung 82445, Taiwan; u0452809@nkfust.edu.tw \\ * Correspondence: clshen@nkfust.edu.tw; Tel.: +886-7-601-1000; Fax: +886-7-601-1386
}

Received: 26 October 2017; Accepted: 6 November 2017; Published: 15 November 2017

\begin{abstract}
In this paper, a novel step-up converter is proposed, which has the particular features of single semiconductor switch, ultra-high conversion ratio, galvanic isolation, and easy control. Therefore, the proposed converter is suitable for the applications of fuel-cell power system. Coupled inductors and switched capacitors are incorporated in the converter to obtain an ultra-high voltage ratio that is much higher than that of a conventional high step-up converter. Even if the turns ratio of coupled inductor and duty ratio are only to be 1 and 0.5 , respectively, the converter can readily achieve a voltage gain of up to 18 . Owing to this outstanding performance, it can also be applied to any other low voltage source for voltage boosting. In the power stage, only one active switch is used to handle the converter operation. In addition, the leakage energy of the two couple inductors can be totally recycled without any snubber, which simplifies the control mechanism and improves the conversion efficiency. Magnetic material dominates the conversion performance of the converter. Different types of iron cores are discussed for the possibility to serve as a coupled inductor. A $200 \mathrm{~W}$ prototype with $400 \mathrm{~V}$ output voltage is built to validate the proposed converter. In measurement, it indicates that the highest efficiency can be up to $94 \%$.
\end{abstract}

Keywords: fuel cells; magnetic material; single semiconductor switch; ultra-high step-up converter

\section{Introduction}

The power generation coming from petro-chemical, coal, and liquefied natural gas (LNG) results in a series of damages like environmental destruction, climate change, and aerial contamination. Therefore, renewable resources have been growing rapidly in recent years to overcome the mentioned problems. Nowadays, green energy is adopted in many fields from household use to industry application. In some applications, such as electric vehicle (EV) and grid-tied renewable-energy system, a high DC voltage to be in the range of 380 to $420 \mathrm{~V}$ is required [1]. Accordingly, incorporating a high step-up DC/DC converter to boost a low-voltage distributed energy resource becomes essential in green energy system.

A high step-up converter developed for photovoltaic (PV) module, wind turbine, or fuel cells is able to boost up a low voltage to a much higher level [2-10], thus, which can accomplish power injecting into a DCbus [11,12]. Magnetic inductor is a main component that is much more important than any other devices in a high step-up converter. A theoretical model of magnetically coupling inductor is studied to analyze the saturation condition [2]. Utilizing parallel paths to share input current for higher power processing is proposed in $[3,4]$. An extra high gain can be achieved by means of voltage multipliers, which has been presented in [5]. Some researchers derive new topologies from boost-type configuration [6,7], while the literature [8] concentrates on interleaved operation and leakage energy recycling. In [9], an isolated step-up converter based on quasi Z-source is 
presented to lower the component count. Combination of boost configuration, coupled inductor and interleaving control is discussed in [10]. For the achievement of high voltage gain, the method that a high step-up converter incorporates coupled inductor [13] and/or switched capacitor [14] is a common approach. However, the shortcomings of galvanic isolation, more active switches, and without high enough voltage gain for direct grid-tied application still exist. For this kind of converter, magnetic device, that is, the coupled inductor, will dominate the power conversion performance of a high step-up converter. The characteristics of a magnetically coupling component should be discussed. Unfortunately, which type of iron core should be feasible and adopted is missed in most literature.

Magnetic core, which includes Ferrite, Molypermalloy Powder (MPP), High Flux, and Kool M $\mu$, are widely used in switching-mode power converters. The characteristics of these magnetic materials, such as flux density, biasing capability, permeability, and core loss, are different. The core loss is of vital importance in power converter design. The following literature discussed core loss from various aspects. A simplified model is proposed in [15] to estimate core loss, which considered the effects of both frequency and temperature. Another one by means of investigating the toroidal cores of Ferrite material explored core loss [16]. In [17], the authors introduced a solution to calculate the core loss of a transformer in switching the power supply with realistic measurements. As for non-sinusoidal input, the literature [18] presented the core loss estimation covering the influences of frequency and duty cycle.

This paper proposes a single-switch isolated ultra-high step-up converter (SIUSC), which can achieve an ultra-high voltage gain for low-voltage input. Its voltage conversion ratio is much higher than that of any other step-up converter. In addition, the SIUSC inherently has the particular features of only one semiconductor switch needed, galvanic isolation, being suitable for any low voltage source, and easy control. In order to characterize a better performance, different materials of magnetic cores are considered and then valued. The converter power stage is depicted in Figure 1. The SIUSC includes several parts: one boost cell, three forward-flyback cells, and one flyback cell, in which the coupled inductor $T_{2}$ performs galvanic isolation. For a better understanding, the advantages of the proposed SIUSC are summarized as follows:

(1) Only one active switch is utilized.

(2) The energy stored in leakage inductance can be recycled.

(3) The voltage conversion ratio is high enough so that SIUSC is capable of dealing with low voltage input.

(4) The structure of the SIUSC has galvanic isolation.

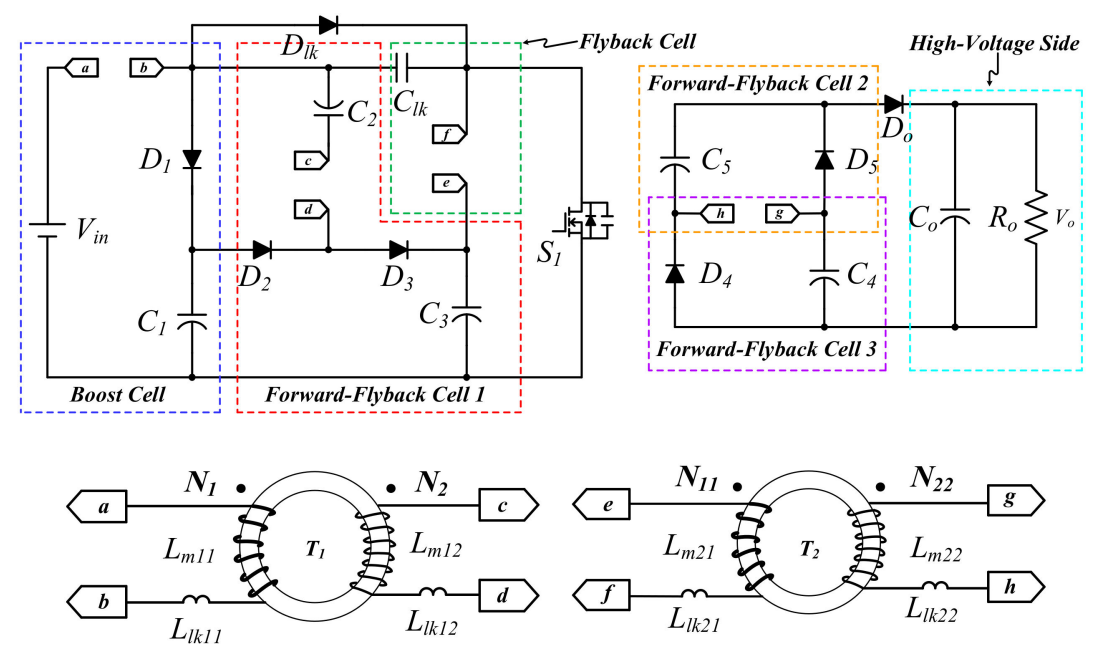

Figure 1. The main power stage of the proposed single-switch isolated ultra-high step-up converter (SIUSC). 
This paper is organized as follows. After the introduction in Section 1, Section 2 details the steady-state analysis of the proposed converter followed by the voltage gain derivation is presented in Section 3. After the inductance design of the coupled inductor operated in continuous conduction mode (CCM) in Section 4, the evaluation of coupled-inductor loss for different magnetic materials is given in Section 5, providing an appropriate selection of magnetic core. Finally, the experimental results measured from a 200-W prototype are given in Section 6 to validate the proposed converter, while the conclusion is summarized in Section 7.

\section{Operation Mode of the Proposed Converter}

Figure 1 is the configuration of the converter, in which symbol definitions are summarized in the following. The $V_{\text {in }}$ and $V_{o}$ signify the terminal voltages at low- and high-voltage sides, respectively. $S_{1}$ is the semiconductor switch, while $D_{1}-D_{5}, D_{l k}$, and $D_{o}$ are power diodes. $C_{1}-C_{5}, C_{l k}$, and $C_{o}$ are capacitors that are employed in the power stage. The magnetically-coupled device $T_{1}$ has $N_{1}$ turns at the primary, $N_{2}$ turns at the secondary, magnetizing inductances $L_{m 11}$ and $L_{m 12}$, and leakage inductances $L_{l k 11}$ and $L_{l k 12}$. Similarly, $N_{11}$ and $N_{22}$ represent the primary and the secondary turns of $T_{2}$, $L_{m 21}$ and $L_{m 22}$ denote the primary and secondary magnetizing inductances, respectively, and $L_{l k 21}$ and $L_{l k 22}$ express the leakage inductances. Before the description of converter operation, some assumptions are made as follows:

(1) In Figure 1, all of the coupled inductors are in CCM.

(2) Parasitic input capacitance of the main switch, $C_{i s s}$, is neglected, and all of the diodes are considered ideal.

(3) The capacitances of all capacitors are considered large enough to ignore the ripples across them. Thus, their voltage can be regarded as constant during one switching period.

(4) The turn ratios of $T_{1}$ and $T_{2}$ are both equal to $n$. That is, $n_{1}=n_{2}=N_{2} / N_{1}=N_{22} / N_{11}$.

The operation of the proposed SIUSC can mainly be divided into six operation modes, whose corresponding equivalents are represented in Figure 2. Key waveforms of the SIUSC over one switching cycle are depicted in Figure 3. The operation of the converter is described mode by mode in the followings.

Mode $1\left[t_{0}, t_{1}\right]$ (see Figure 2a): The converter operation over one switch cycle starts at Mode 1 , in which the switch $S_{1}$ is turned $O N$ at $t=t_{0}$. The magnetizing inductors $L_{m 11}$ and $L_{m 21}$ absorb energy from $V_{\text {in }}$ and $C_{4}$, respectively. Meanwhile, capacitor $C_{1}$ and the secondary of $T_{1}$ release energy to capacitor $C_{2}$ via $D_{2}$ and $S_{1}$. Once the switch $S_{1}$ is turned OFF, operation of the converter enters into the next mode.

Mode $2\left[\boldsymbol{t}_{1}, \boldsymbol{t}_{\mathbf{2}}\right]$ (see Figure 2b): In Mode 2, switch $S_{1}$ is in OFF state. During this time interval, the energy of $L_{l k 11}$ is forwarded to capacitor $C_{1}$ via diode $D_{1}$. Similarly, the energy of $L_{l k 21}$ is dumped to $C_{l k}$ via $D_{3}$. When $i_{D 2}$ drops to zero, this mode ends.

Mode $3\left[t_{2}, t_{3}\right]$ (see Figure $2 c$ ): The $S_{1}$ remains the same status as in Mode 2 . The energy of $L_{m 11}$ is forwarded to capacitor $C_{1}$. Meanwhile, the capacitor $C_{3}$ is charged via the loop of $V_{i n}-N_{1}-C_{2}-N_{2}-D_{3}$. When the capacitor $C_{l k}$ stops absorbing energy from $L_{l k 21}$, this mode ends.

Mode $4\left[t_{3}, t_{4}\right]$ (see Figure 2d): During the interval of Mode 4 , switch $S_{1}$ is in OFF state. Input voltage $V_{\text {in }}$ and magnetizing inductance $L_{m 11}$ proceed with energy releasing toward $C_{1}$ and $C_{3}$ via $D_{1}$ and $D_{3}$, respectively. In addition, the $L_{m 21}$ begins pumping its energy to output capacitor $C_{0}$ via the loop of $C_{4}-N_{22}-C_{5}-D_{0}-C_{0}$. Since $C_{4}$ and $C_{5}$ are in series at this energy-pumping loop, both capacitors also forward their energy to $C_{0}$. The current following through $D_{1}, i_{D 1}$, decreases. Mode 4 ends when $i_{D 1}$ is equal to zero.

Mode $5\left[t_{4}, t_{5}\right]$ (see Figure 2e): The switch has the same status as in Mode 4 . Since the capacitor $C_{1}$ has been fully charged, the $L_{m 11}$ and $L_{m 21}$ pump energy to $C_{3}$ and output, respectively. This mode will end as current $i_{D o}$ falls to zero. 
Mode $6\left[t_{5}, t_{6}\right]$ (see Figure 2f): In this mode, switch $S_{1}$ is in ON-state again. The energy stored in capacitor $C_{l k}$ is drawn out via $S_{1}$; that is, the leakage energy of $L_{l k 21}$ is successfully recycled. This mode ends when $i_{D l k}$ starts to increase, and converter operation over one switching cycle is completed.
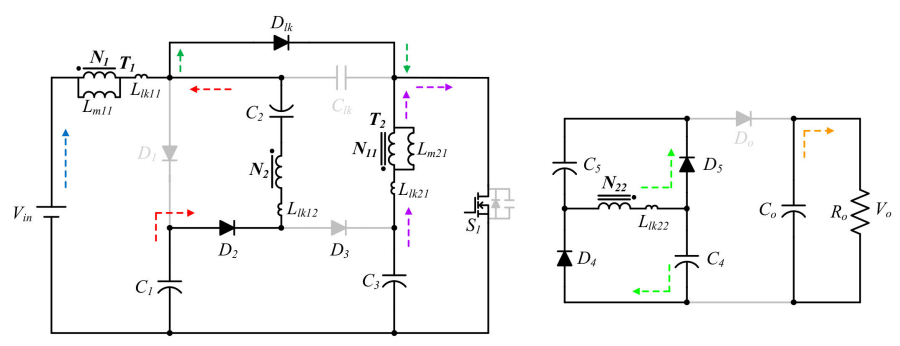

(a)
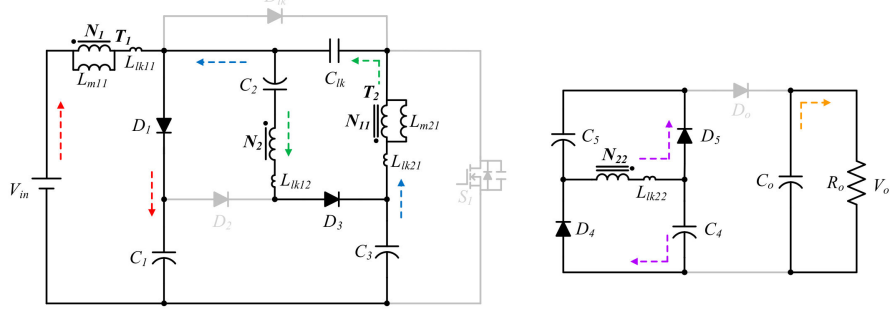

(b)
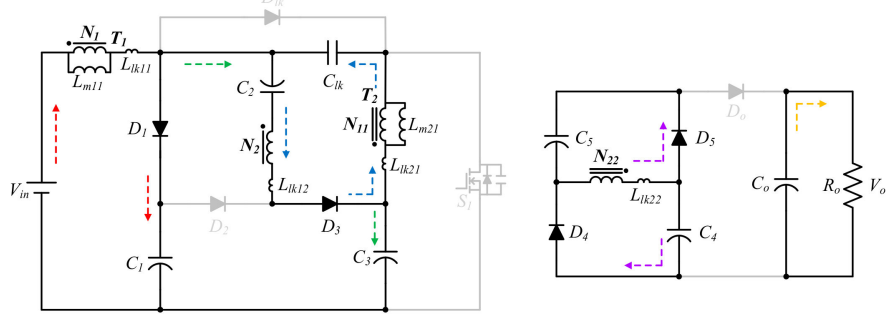

(c)
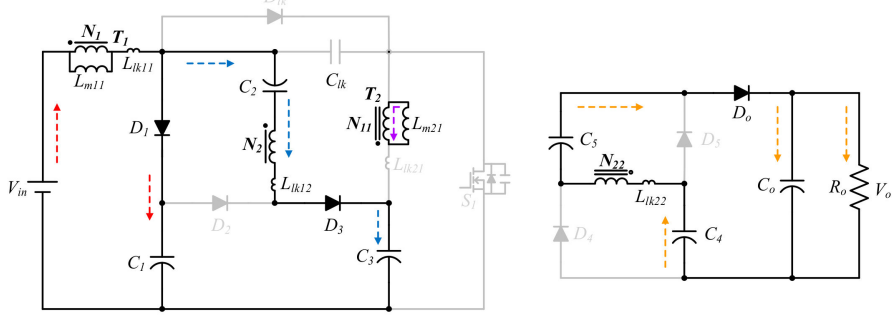

(d)
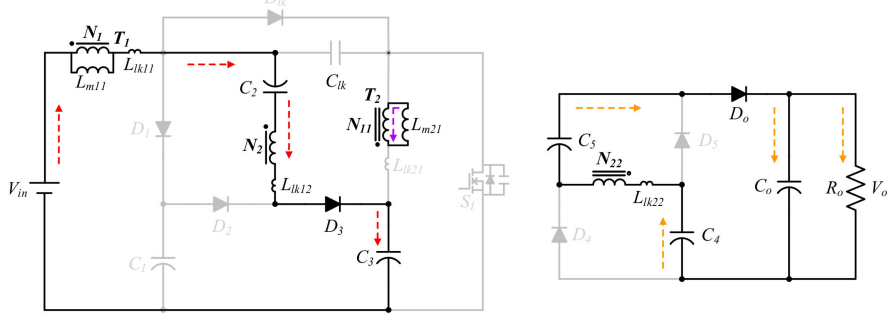

(e)

Figure 2. Cont. 


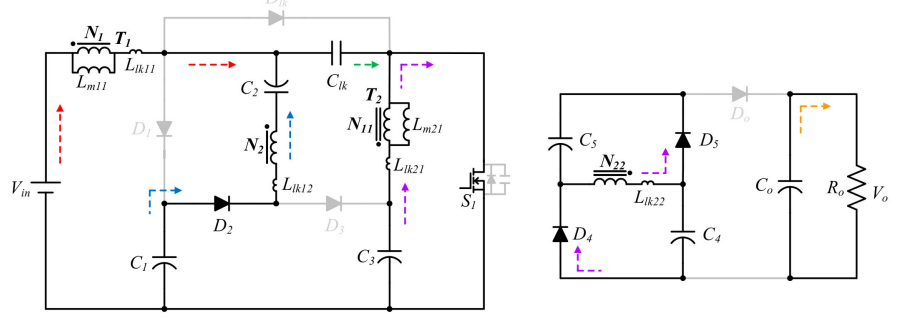

(f)

Figure 2. Mode equivalents of the proposed SIUSC over one switching cycle. (a) Mode $1\left[t_{0}, t_{1}\right]$; (b) Mode $2\left[t_{1}, t_{2}\right]$; (c) Mode $3\left[t_{2}, t_{3}\right]$; (d) Mode $4\left[t_{3}, t_{4}\right]$; (e) Mode $5\left[t_{4}, t_{5}\right]$; and (f) Mode $6\left[t_{5}, t_{6}\right]$.

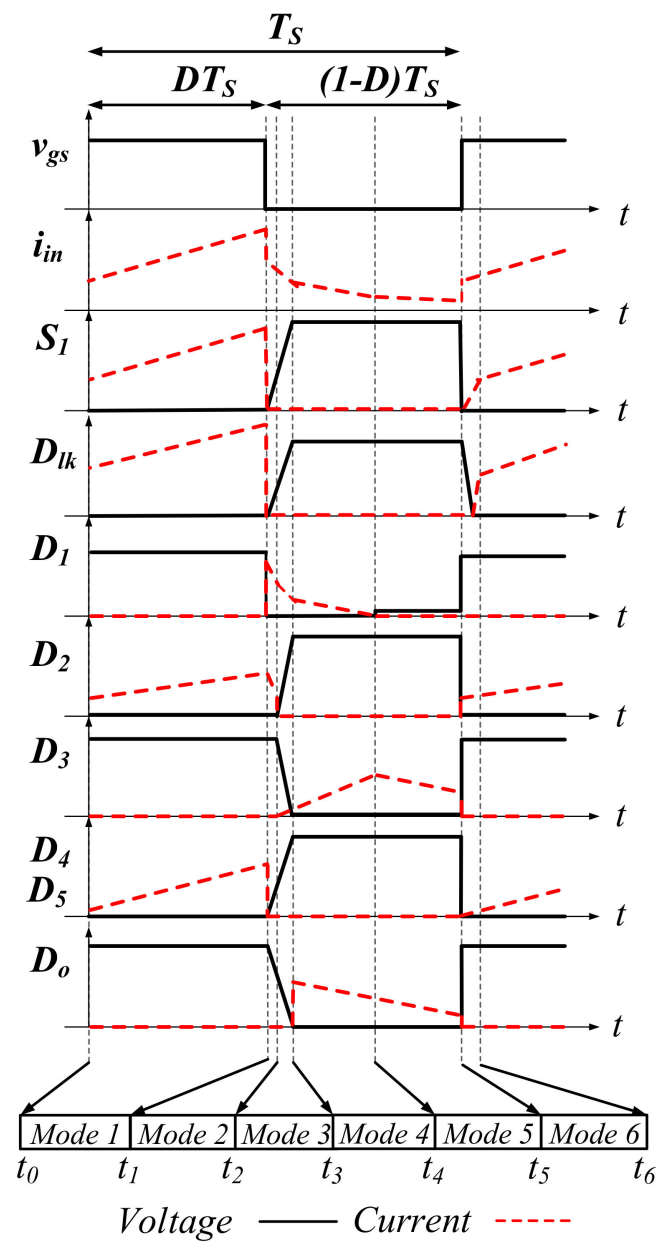

Figure 3. The key waveforms of the proposed SIUSC.

\section{Voltage Gain Derivation}

In this section, the voltage conversion ratio of SIUSC will be derived. For high power applications, the SIUSC is designed to operate in CCM. Furthermore, the assumptions made in the previous section are also considered. In addition, the phenomenon that occurs during switching transient is ignored.

It can be found that the output voltage $V_{o}$ is equal to the sum of $V_{C 4}, n_{2} V_{L m 21}$, and $V_{C 5}$. Hence, in order to determine the voltage ratio of $V_{o}$ to $V_{i n}$, the voltages of $V_{C 1}, V_{C 2}, V_{C 3}, V_{C 4}, V_{C 5}, V_{C l k}$, 
and $V_{C_{0}}$ have to be obtained in advance. Firstly, the voltage across $C_{1}$ can be determined by applying volt-second balance criterion (VSBC) to $L_{m 11}$, which can yield.

$$
V_{C 1}=\frac{1}{1-D} V_{i n}
$$

As for $V_{C 2}$, the voltage across $C_{2}$ is the sum of $V_{C 1}$ and $n_{1} V_{L m 11}$ when $S_{1}$ is in ON state. Thus, $V_{\mathrm{C} 2}$ can be found by

$$
V_{C 2}=\frac{1+n_{1}(1-D)}{1-D} V_{i n}
$$

The $V_{C 3}$ is equal to the series voltage of $V_{i n}, V_{L m 11}, n_{1} V_{L m 11}$, and $V_{C 2}$, accordingly, which can be

$$
V_{C 3}=\frac{2+n_{1}}{1-D} V_{\text {in }}
$$

The capacitors $C_{4}$ and $C_{5}$ are charged simultaneously while $S_{1}$ is closed. Thus, both voltages $V_{C 4}$ and $V_{C 5}$ are identical and equal to $n_{2} V_{L m 21}$, and then the following relationship holds:

$$
V_{C 4}=V_{C 5}=\frac{n_{2}\left(2+n_{1}\right)}{1-D} V_{i n} .
$$

With respect to the voltage across capacitor $C_{l k}$, the voltage $V_{C l k}$ can be determined from $V_{L m 12}$, $V_{C 2}$ and $V_{L m 21}$. It is given by

$$
V_{C l k}=\frac{1+n_{1}+D}{(1-D)^{2}} V_{i n}
$$

Since the output voltage $V_{o}=V_{C 4}+V_{C 5}-n_{2} V_{L m 21}$, the voltage $V_{C o}$ can be determined from

$$
V_{C o}=V_{o}=\left(\frac{2+n_{1}}{1-D} n_{2}+\frac{2+n_{1}}{1-D} n_{2}-\frac{D\left(2+n_{1}\right)}{1-D} n_{2}\right) V_{\text {in }}
$$

Once the voltages $V_{C 1}, V_{C 2}, V_{C 3}, V_{C 4}, V_{C 5}, V_{C l k}$ and $V_{C o}$ are given in terms of $V_{i n}$, the conversion ratio of output to input voltages, $V_{o} / V_{i n}$, can readily be found by

$$
\frac{V_{o}}{V_{\text {in }}}=\frac{n_{2}\left(2+n_{1}\right)(2-D)}{(1-D)^{2}}
$$

\section{Inductance Design for CCM}

The boundary condition of $i_{L m 1}$ is designed at $20 \%$ of full load for overall efficiency consideration. That is, the output resistance is $4000 \Omega$ at boundary. The maximum and minimum currents of $i_{L m 1}$, denoted as $I_{L m 1, \max }$ and $I_{L m 1, \min }$, respectively, can be calculated by

$$
I_{L m 1, \max }=I_{L m 1, a v g}+\frac{\Delta i_{L m 1}}{2}
$$

and

$$
I_{L m 1, \min }=I_{L m 1, a v g}-\frac{\Delta i_{L m 1}}{2},
$$

where $I_{L m 1, a v g}$ is the average value of $i_{L m 1}$ and $\Delta i_{L m 1}$ stands for the current change on the magnetizing inductance over switch ON or OFF interval.

To make sure the magnetizing inductance $L_{m 1}$ is in CCM, the current $I_{L m 1, m i n}$ should be greater than zero. Additionally, the $\Delta i_{L m 1}$ and $I_{L m 1, \text { avg }}$ can be determined as follows:

$$
\Delta i_{L m 1}=\frac{v_{L m 1}}{L_{m 1}} D T_{s}=\frac{V_{o}(1-D)^{2} D}{f_{s} L_{m 1}(2-D)\left(2+n_{1}\right) n_{2}}
$$


and

$$
I_{L m 1, a v g}=\frac{(2-D)\left(2+n_{1}\right) n_{2}}{(1-D)^{2}} I_{o},
$$

where $f_{s}$ represents the switching frequency in hertz. Thus,

$$
I_{L m 1, \min }=\frac{(2-D)\left(2+n_{1}\right) n_{2}}{(1-D)^{2}} I_{o}-\frac{\Delta i_{L m 1}}{2}=0,
$$

By rearranging the Equations (9)-(12), the minimum value that makes coupled inductor $T_{1}$ operate in CCM is obtained as:

$$
L_{m 1}=\frac{D(1-D)^{4} R_{o}}{2 f_{s} n_{2}^{2}\left(2+n_{1}\right)^{2}(2-D)^{2}}
$$

\section{Magnetic Core Selection}

There are three types of toroidal cores, MPP, High Flux, and Kool M $\mu$, which are widely adopted in switching power supply. They are also considered to serve as the magnetic core of the coupled inductors in SIUSC and are discussed in this section. Based on (13), if given that $D=0.47, f_{s}=50 \mathrm{kHz}$, $n_{1}=n_{2}=1$, and $R_{o}=4 \mathrm{k} \Omega$, the inductance of $L_{m 1}$ will be $70.4 \mu \mathrm{H}$. In addition, in order to process a power of $200 \mathrm{~W}$, the $I_{L m 1, a v g}$ should be $8.33 \mathrm{~A}$. At this situation, current ripple $\Delta i_{L m 1}$ is limited within $2 \mathrm{~A}$. As a result, the maximum current of $L_{m 1}, I_{L m 1, \max }$ is calculated as

$$
I_{L m 1, \max }=I_{L m 1, a v g}+\frac{\Delta i_{L m 1}}{2}=9.33 \mathrm{~A}
$$

The maximum increment on flux density of a specific magnetic material, $\Delta B_{\max }$, has to be known to avoid a coupled inductor from going saturation. The $\Delta B_{\max }$ can be found from the manufacturer's datasheet. With the values of maximum magnetizing current, maximum flux change, switching frequency, and volume of core, it can benefit a designer to assess the loss of a coupled inductor and then to choose an appropriate magnetic core [19].

\subsection{MPP Core}

The core loss of MPP can be calculated by

$$
P_{\text {core loss-MPP }}=53.05 B^{2.06} f_{s}^{1.56},
$$

in which the $B$ is flux density and $f_{s}$ is operation frequency. A corresponding plot is shown in Figure 4 , in which the permeability equals $125 \mu \mathrm{H} / \mathrm{m}$. In general, the $B$ will fall within the range from 0.2 to 0.25 Tesla. If an MPP core with part No. 55324-A2, whose volume is $6.088 \mathrm{~cm}^{3}$, is considered, the associated power loss density will be $861.39 \mathrm{~mW} / \mathrm{cm}^{3}$ under the design conditions that $B$ is given as 0.2 Tesla and $f_{s}=50 \mathrm{kHz}$. As a result, the core loss is computed as $5.244 \mathrm{~W}$. 


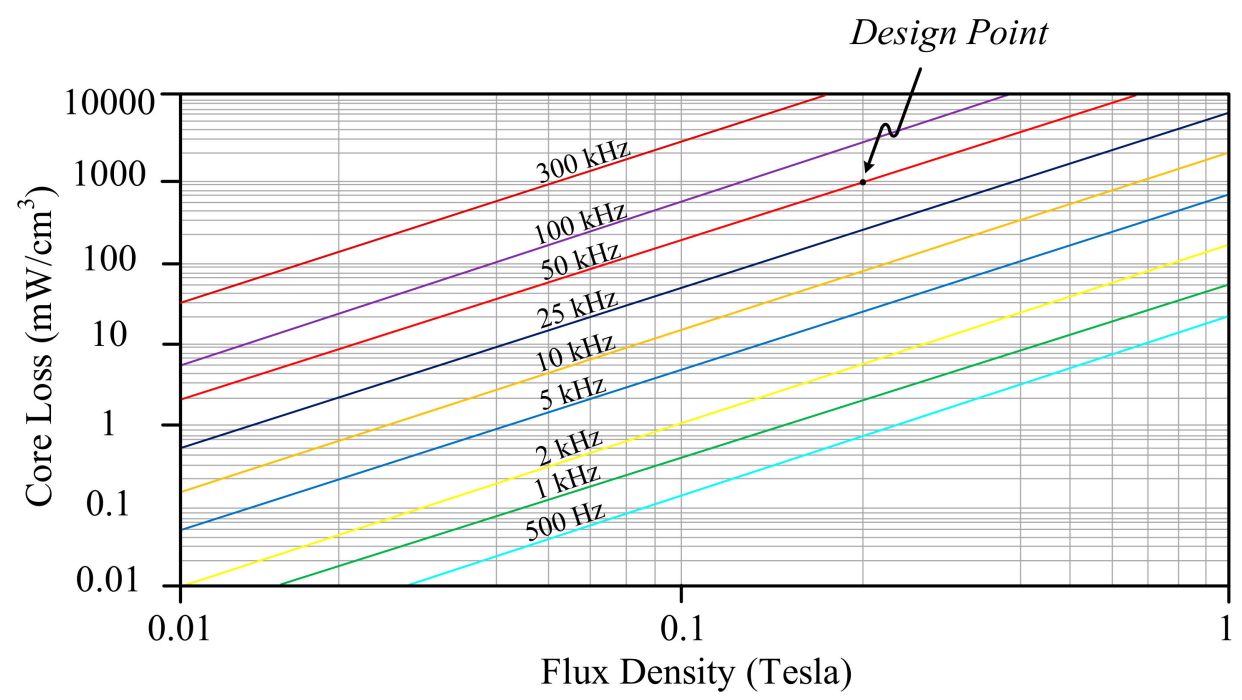

Figure 4. The relationship between core loss and flux density of Molypermalloy Powder (MPP) while permeability equals $125 \mu \mathrm{H} / \mathrm{m}$.

Based on the given values of $L_{m 1}, I_{L m 1, \max }, B$, and the effective cross-section area of $0.678 \mathrm{~cm}^{2}$ for MPP 55324-A2, the turns of primary side can be determined as follows:

$$
N_{M P P}=\frac{L_{m 1} \Delta I_{\max }}{\Delta B_{\max } A_{e}} \times 10^{-2}=\frac{70.4 \times 9.33}{0.375 \times 0.678} \times 10^{-2}=25.83
$$

Since turns ratio should be an integer, $N_{M P P}$ is chosen as 26 turns. An average length of one turn is $3.44 \mathrm{~cm}$, which yields the total length of the winding at the primary is

$$
l_{M P P}=26 \times 3.44=894.4 \mathrm{~mm}
$$

A copper wire with cross-section area of $0.518 \mathrm{~mm}^{2}$ is adopted for a maximum carried current of $11 \mathrm{~A}$. The resistivity of copper, $\rho$, is $2.3 \times 10^{-6} \Omega-\mathrm{m}$. Thus, resistance of the primary winding is calculated by

$$
R_{M P P}=\rho \frac{l}{A}=2.3 \times 10^{-6} \frac{894.4}{0.518}=3.971 \mathrm{~m} \Omega
$$

Suppose that the turns ratio of coupled inductor is unity. The total copper loss is calculated as

$$
P_{\text {copper-MPP }}=9.33^{2} \times 3.971 \times 2=691.17 \mathrm{~mW}
$$

\subsection{High Flux Core}

With respect to the core loss of the magnetic material of High Flux, it can be estimated by

$$
P_{\text {core loss-High Flux }}=246 B^{2.23} f_{s}^{1.47}
$$

Figure 5 illustrates the relationship of core loss versus flux density under different switching frequencies, while permeability is $125 \mu \mathrm{H} / \mathrm{m}$. If 0.2 -Tesla flux density is the operation point and the core of High Flux 58324-A2 is chosen, then the associated core loss density will be $2136.57 \mathrm{~mW} / \mathrm{cm}^{3}$ under $50-\mathrm{kHz}$ switching frequency. Since the volume of the core $58324-\mathrm{A} 2$ is $6.088 \mathrm{~cm}^{3}$, core loss of the High Flux magnetic coupled inductor is $13.007 \mathrm{~W}$. 


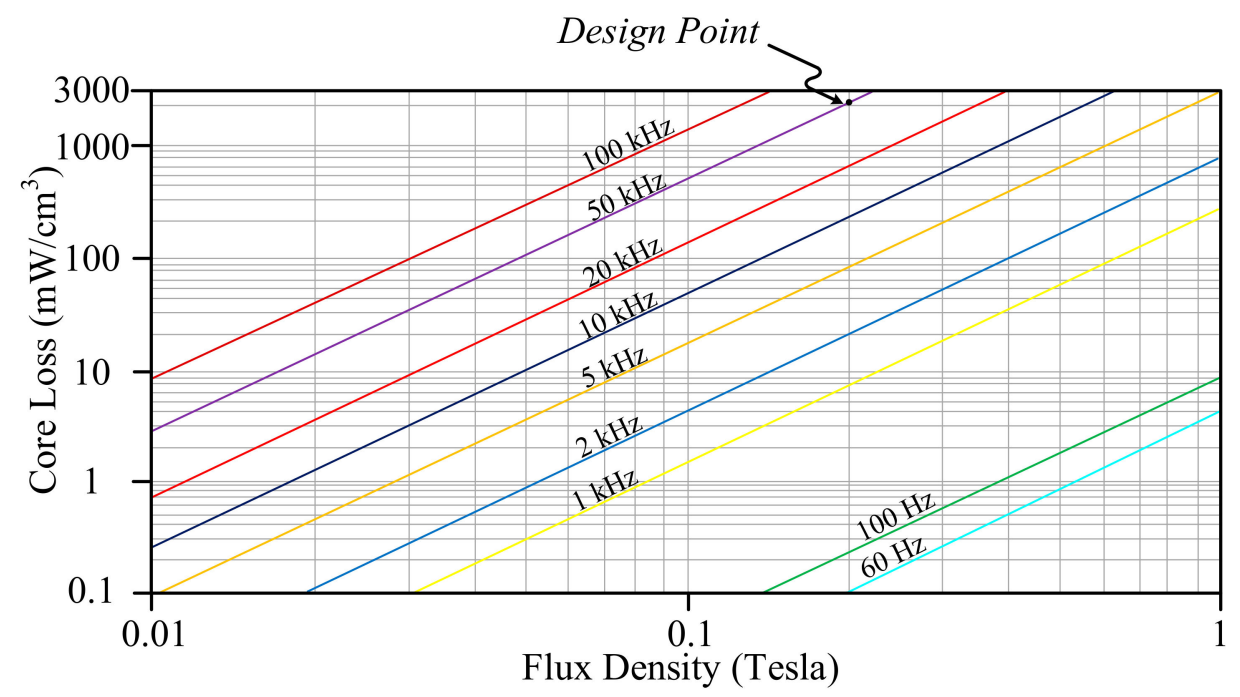

Figure 5. The relationship between core loss and flux density of High Flux, while permeability equals $125 \mu \mathrm{H} / \mathrm{m}$.

For High Flux 58324-A2, the allowed maximum variation at flux density is up to 0.75 Tesla. With the same conditions in MPP, the turns of primary side can be determined as follows:

$$
N_{\text {High Flux }}=\frac{L_{m 1} \Delta I_{\text {max }}}{\Delta B_{\max } A_{e}} \times 10^{-2}=\frac{70.4 \times 9.33}{0.75 \times 0.678} \times 10^{-2}=12.91
$$

Since turns ratio should be an integer, $N_{\text {High Flux }}$ is chosen as 13 turns. An average length of one turn is $3.44 \mathrm{~cm}$ for High Flux 58324-A2. Therefore, the total length of the winding at the primary is

$$
l_{\text {High Flux }}=13 \times 3.44=447.2 \mathrm{~mm}
$$

Resistance of the primary winding is calculated as

$$
R_{\text {High Flux }}=\rho \frac{l}{A}=2.3 \times 10^{-6} \frac{447.2}{0.518}=1.985 \mathrm{~m} \Omega
$$

Then, the total copper loss of the coupled inductor with High Flux core is

$$
P_{\text {copper-High Flux }}=9.33^{2} \times 1.985 \times 2=345.58 \mathrm{~mW}
$$

\subsection{Kool M $\mu$ Core}

Another magnetic core widely adopted in switching power circuit is the type of Kool $\mathrm{M} \mu$. Its core loss can be determined by the following equation.

$$
P_{\text {core loss }- \text { Kool M } \mu}=91.58 B^{2.2} f_{s}^{1.63}
$$

Based on (25), a corresponding plot is presented in Figure 6, while permeability equals $125 \mu \mathrm{H} / \mathrm{m}$. A Kool M $\mu$ core with part no. 77324-A2 is chosen, whose volume is $6.088 \mathrm{~cm}^{3}$. Its associated power loss density will be $1560.94 \mathrm{~mW} / \mathrm{cm}^{3}$ under the conditions, $B=0.2$ Tesla and $f_{s}=50 \mathrm{kHz}$, which results in a core loss of $9.503 \mathrm{~W}$. 


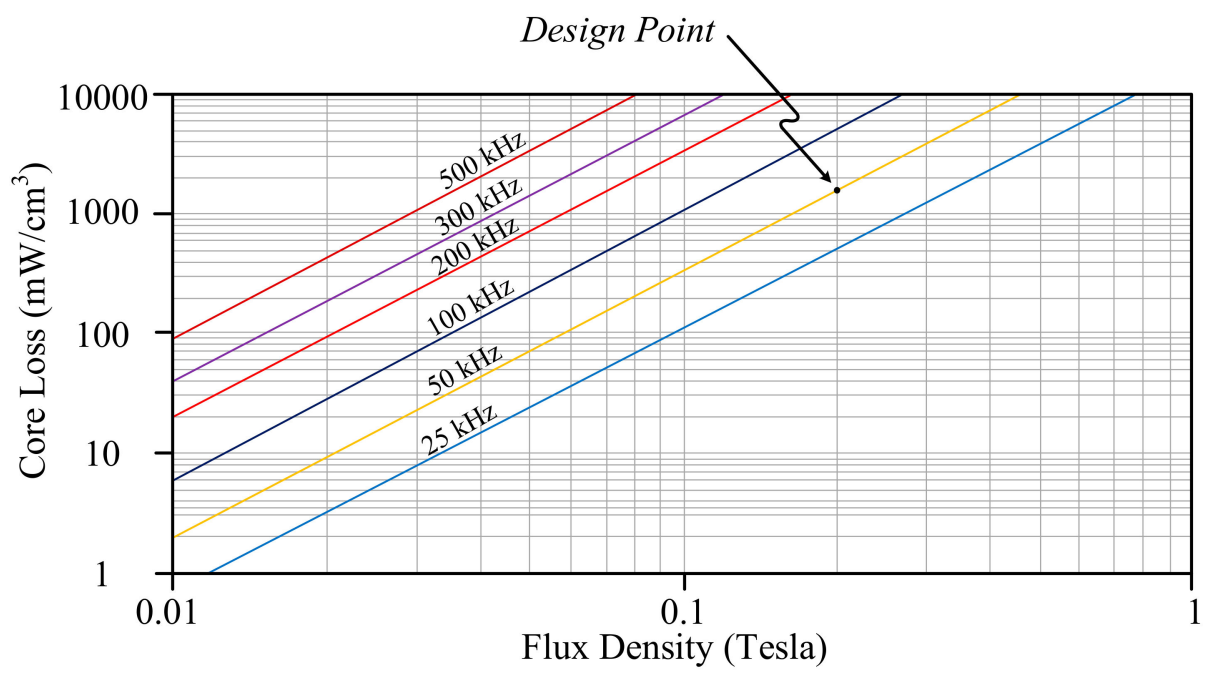

Figure 6. The relationship between core loss and flux density of Kool $\mathrm{M} \mu$, while permeability equals $125 \mu \mathrm{H} / \mathrm{m}$.

The maximum variation of flux density of Kool $\mathrm{M} \mu$ is 0.525 Tesla. Similarly, with the same given values as in the discussions of MPP and High Flux cores, the turns at the primary winding is determined as

$$
N_{\text {Kool M } \mu}=\frac{L_{m 1} \Delta I_{\max }}{\Delta B_{\max } A_{e}} \times 10^{-2}=\frac{70.4 \times 9.33}{0.525 \times 0.678} \times 10^{-2}=18.45
$$

Thus, $N_{\text {Kool M } \mu}$ is chosen as 18 turns. Because an average length of one turn is around $3.44 \mathrm{~cm}$, the total length of the primary winding is $619.2 \mathrm{~mm}$. The resistance of the primary winding is calculated as

$$
R_{\mathrm{Kool} \mathrm{M} \mu}=\rho \frac{l}{A}=2.3 \times 10^{-6} \frac{619.2}{0.518}=2.749 \mathrm{~m} \Omega
$$

In addition, the copper loss of a coupled inductor with unity turns ratio can be estimated as

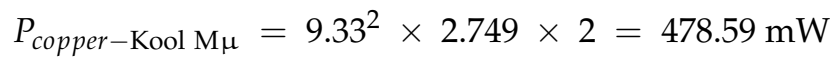

\section{Experimental Results}

To validate the proposed SIUSC, a 200-W prototype is built with the specifications and components that are summarized in Table 1, while the measuring equipment are shown in Table 2 . In the experiment, the input and output voltages are 24 and $400 \mathrm{~V}$, respectively. The implementation of the coupled inductors $T_{1}$ and $T_{2}$ are based on MPP 55324-A2 core with a turns ratio of 1:1, which have magnetizing inductances 70.4 and $70.6 \mu \mathrm{H}$, respectively, which are measured by MICRTEST 6377 (MICROTEST Corp., Taipei, Taiwan). Current-mode PWM IC, UC3843 (TEXAS INSTRUMENTS, Dallas, TX, USA), is chosen as converter controller. The power MOSFET IRFP4332PbF (INTERNATIONAL RECTIFIER, El Segundo, CA, United States) with 200-m $\Omega$ on-state resistance of $R_{d s(o n)}$ is served as main switch. Power Schottky Rectifier SBL6045PT, of which the forward voltage is $0.44 \mathrm{~V}$, is in charge of $D_{1}$ and DSSK60-02AR with 0.7-V forward voltage is for $D_{2}, D_{3}$ and $D_{l k}$. In addition, ultrafast power diode BYV34 is used for $D_{4}, D_{5}$, and $D_{0}$, which has a forward voltage of $1.05 \mathrm{~V}$. The input of the prototype is powered by the voltage power supply, IDRC CDSP-060-100C (IDRC, Taipei, Taiwan). Meanwhile, the converter output is connected to an electronic load, GW Instek PEL-2041 (GWINSTEK, Taipei, Taiwan). All of the waveforms are measured by oscilloscope KEYSIGHT DSO-X 3024A (KEYSIGHT, Santa Rosa, CA, USA). 
Figures 7-9 are the practical measurements. Figure 7 illustrates the input current of the proposed converter, which verifies that the SIUSC indeed operates in CCM. Figure 8 shows the measurements from active switch $S_{1}$, in which it can be observed that the $v_{d s 1}$ can be clamped to a lower voltage stress. This voltage-clamped effect also demonstrates the feature of leakage energy recycling. Figure 9 shows the transient response of the converter under step load change, which confirms that the SIUSC can intrinsically achieve excellent performance. Figure 10 depicts the measured efficiency of the prototype, where the peak efficiency is around $94 \%$ at $80 \mathrm{~W}$. Figure 11 shows the photo of test bench, where the equipment for practical measurement have been listed in Table 2. In Figure 11, the length, width, and height of the main circuit are around 13.8, 8.04, and $3.4 \mathrm{~cm}$, respectively.

Table 1. Specifications and components used in experiments.

\begin{tabular}{cc}
\hline Symbols & Values \& Types \\
\hline$V_{\text {in }}$ (input voltage) & $24 \mathrm{~V}$ \\
$V_{o}$ (Output Voltage) & $400 \mathrm{~V}$ \\
$P_{o}$ (output power) & $200 \mathrm{~W}$ \\
$f_{s}$ (switch frequency) & $50 \mathrm{kHz}$ \\
$n_{1}, n_{2}$ (transformer turns ratio) & 1 \\
$L_{m 11}$ (magnetizing inductance) & $70.4 \mu \mathrm{H}$ \\
$L_{m 21}$ (magnetizing inductance) & $70.6 \mu \mathrm{H}$ \\
$L_{l k 11}$ (Leakage inductance) & $1.45 \mu \mathrm{H}$ \\
$L_{l k 21}$ (Leakage inductance) & $1.45 \mu \mathrm{H}$ \\
$C_{1}, C_{2}, C_{3}$ (Capacitance) & $47 \mu \mathrm{F}$ \\
$C_{l k}$ (Capacitance) & $5 \mu \mathrm{F}$ \\
$C_{4}, C_{5}$ (Capacitance) & $100 \mu \mathrm{F}$ \\
$C_{o}$ (Capacitance) & $220 \mu \mathrm{F}$ \\
$S_{1}$ (Switch) & IRFP4332PbF \\
$D_{1}$ & SBL6045PT \\
$D_{2}, D_{3}, D_{l k}$ (Diodes) & DSSK60-02AR \\
$D_{4}, D_{5}, D_{o}$ (Diodes) & BYV34 \\
\hline
\end{tabular}

Table 2. Measurement Equipment.

\begin{tabular}{cc}
\hline Current Probe & Tektronix TCP312, 30ADL \\
\hline Power Supply & iDRC CDSP-060-100C \\
Oscilloscope & Agilent DSO-X 3024A 200MHz 4GSa/s \\
DC Load & GW Instek PEL-2041 0 A/10 A 2.5 V /500 V 350 W \\
LCR Meter & MICROTEST 6377 \\
\hline
\end{tabular}

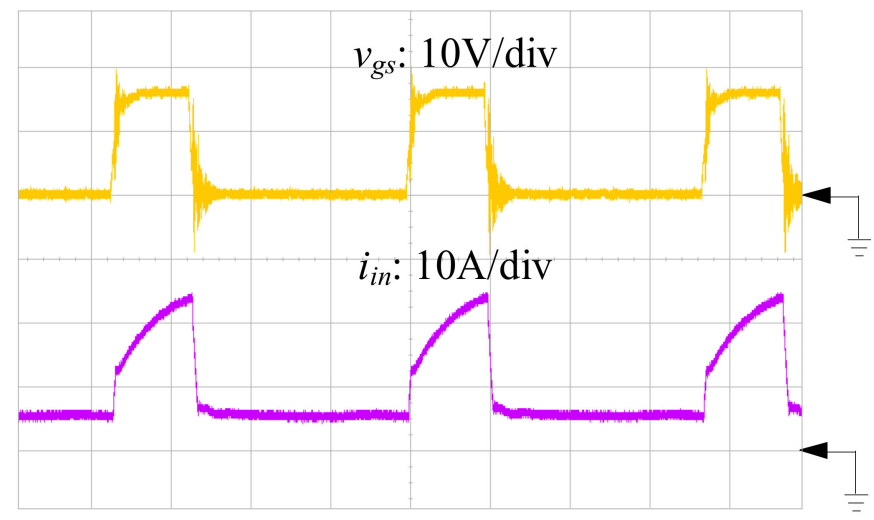

Figure 7. The measured waveforms of control signal $v_{g s}$ and input current $i_{\text {in }}$. 


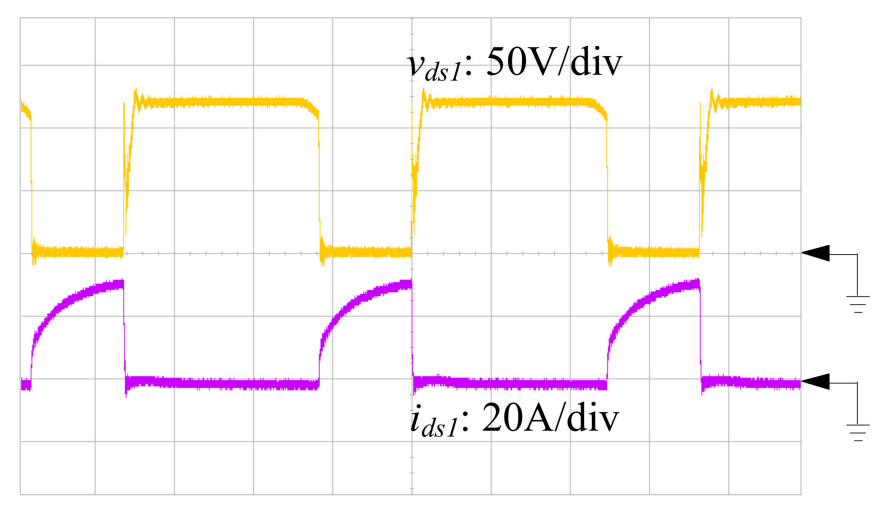

Figure 8. The measured waveforms from active switch $S_{1}$.

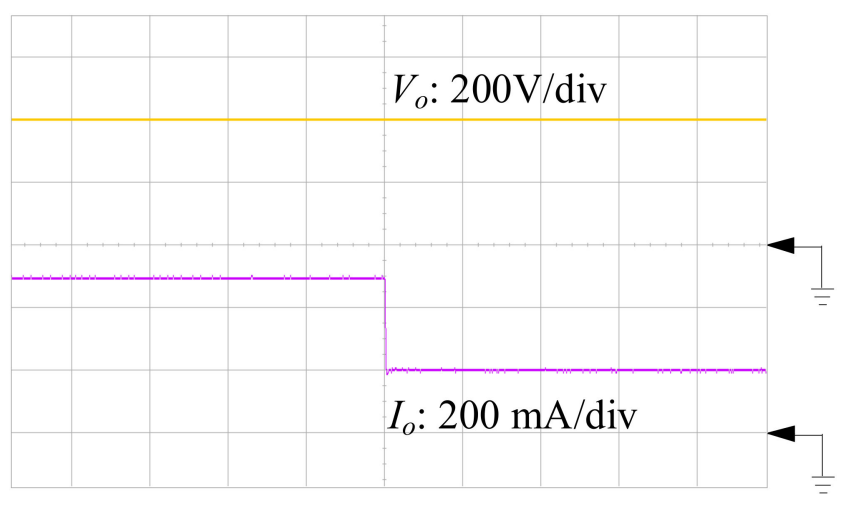

Figure 9. Measured output voltage and current waveforms to illustrate transient response under step change.

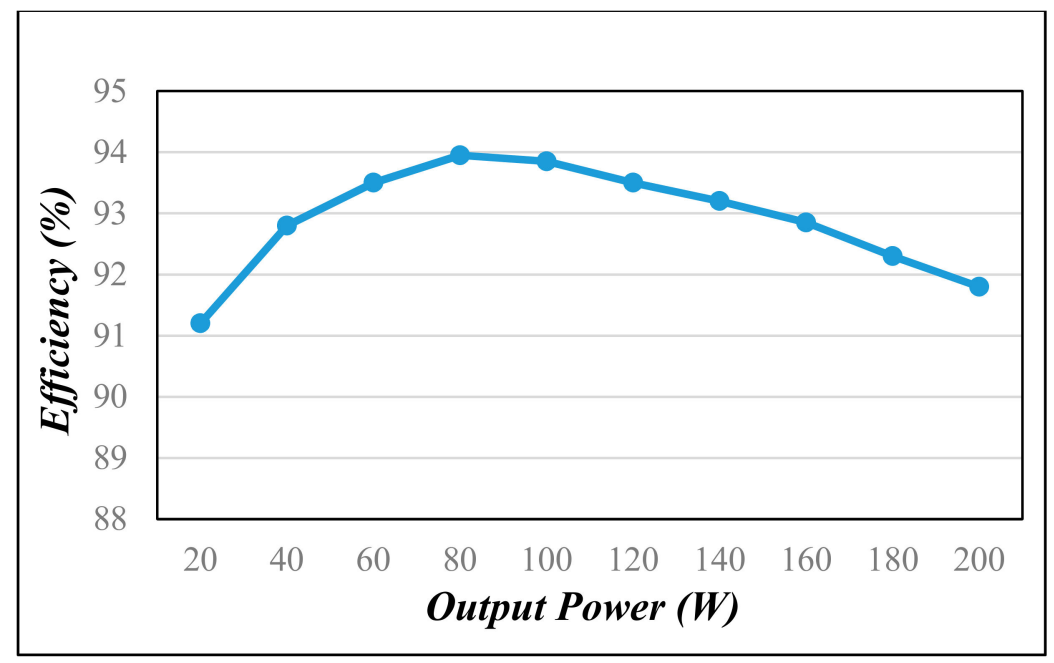

Figure 10. The measured efficiency of the proposed converter. 


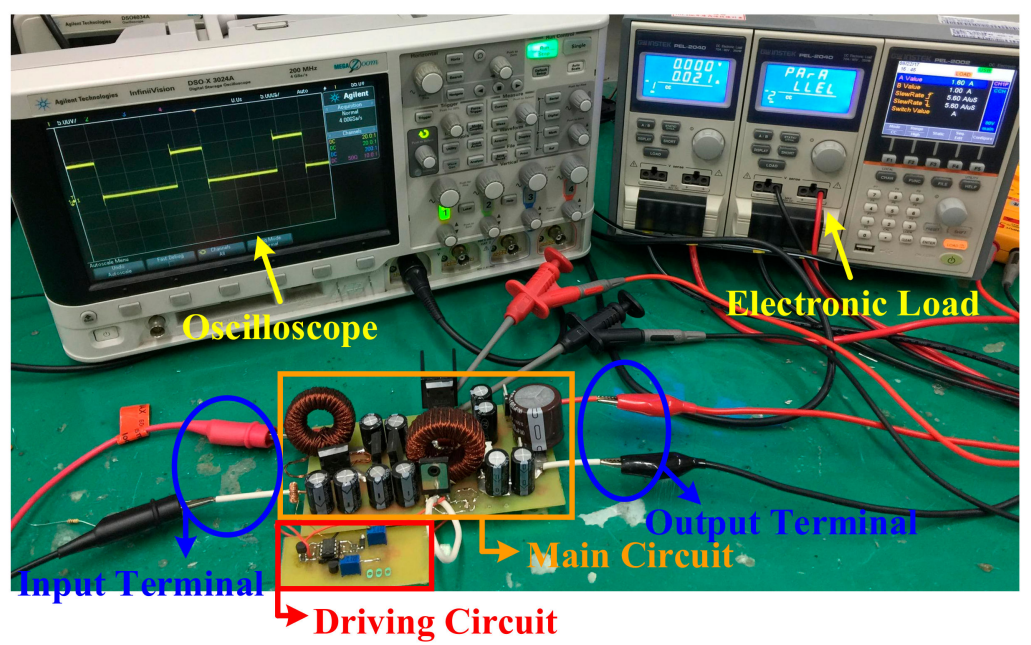

Figure 11. The photo of the experimental setup.

\section{Conclusions}

This paper proposes a novel single-switch isolated ultra-high step-up DC/DC converter, which is applicable to fuel cells, PV module, and battery system. The main contribution of this paper is that an ultra-high voltage conversion ratio can be easily achieved even under a low turns ratio and duty ratio. This outstanding performance make the SIUSC be much more suitable for any low voltage source to boost its input voltage. In addition, the loss of magnetic components is assessed and discussed for three different types of toroidal cores. A $24 / 400 \mathrm{~V} 200 \mathrm{~W}$ prototype has been built and examined to verify the feasibility of the SIUSC. The measurements indicate the converter having a maximum efficiency of $94 \%$.

Acknowledgments: The authors would like to convey their appreciation for grant support from the Ministry of Science and Technology (MOST) of Taiwan under its grant with reference number MOST 106-3113-E-006-010-.

Author Contributions: Chih-Lung Shen and Heng Liou conceived and designed the circuit in addition to magnetic material study. Heng Liou performed simulations, carried out the prototype, and analyzed data with guidance from Chih-Lung Shen. Chih-Lung Shen revised the manuscript for submission.

Conflicts of Interest: The authors declare that there is no conflict of interests.

\section{References}

1. Zhang, Y.; Shi, J.; Zhou, L.; Li, J.; Sumner, M.; Wang, P.; Xia, C. Wide input-voltage range boost three-level DC-DC converter with quasi-Z source for fuel cell vehicles. IEEE Trans. Power Electron. 2017, 32, 6728-6738. [CrossRef]

2. Kefalas, T.D.; Kladas, A.G. Analysis of transformers working under heavily saturated conditions in grid-connected renewable-energy systems. IEEE Trans. Ind. Electron. 2012, 59, 2342-2350. [CrossRef]

3. Yang, B.; Li, W.; Zhao, Y.; He, X. Design and analysis of a grid-connected photovoltaic power system. IEEE Trans. Power Electron. 2010, 25, 992-1000. [CrossRef]

4. Cao, Y.; Samavatian, V.; Kaskani, K.; Eshraghi, H. A novel nonisolated ultra-high-voltage-gain DC-DC converter with low voltage stress. IEEE Trans. Ind. Electron. 2017, 64, 2809-2819. [CrossRef]

5. Shen, C.-L.; Chiu, P.-C.; Lee, Y.-C. Novel interleaved converter with extra-high voltage gain to process low-voltage renewable-energy generation. Energies 2016, 9, 871. [CrossRef]

6. Wong, Y.-S.; Chen, J.-F.; Liu, K.-B.; Hsieh, Y.-P. A novel high step-up DC-DC converter with coupled inductor and switched clamp capacitor techniques for photovoltaic systems. Energies 2017, 10, 378. [CrossRef]

7. Wu, Y.-E.; Wu, Y.-L. Design and implementation of a high efficiency, low component voltage stress, single-switch high step-up voltage converter for vehicular green energy systems. Energies 2016, 9, 772. [CrossRef] 
8. Lu, Y.; Xing, Y.; Wu, H. A PWM plus phase-shift controlled interleaved isolated boost converter based on semiactive quadrupler rectifier for high step-up applications. IEEE Trans. Ind. Electron. 2016, 63, 4211-4221. [CrossRef]

9. Nguyen, M.K.; Lim, Y.C.; Choi, J.H.; Cho, G.B. Isolated high step-up DC-DC converter based on quasi-switched-boost network. IEEE Trans. Ind. Electron. 2016, 63, 7553-7562. [CrossRef]

10. Tseng, S.-Y.; Wang, H.-Y. A photovoltaic power system using a high step-up converter for DC load applications. Energies 2013, 6, 1068-1100. [CrossRef]

11. Shen, C.-L.; Chen, H.-Y.; Chiu, P.-C. Integrated three-voltage-booster DC-DC converter to achieve high voltage gain with leakage-energy recycling for PV or fuel-cell power systems. Energies 2015, 8, 9843-9859. [CrossRef]

12. Pinto, R.; Mariano, S.; Calado, M.; de Souza, J. Impact of rural grid-connected photovoltaic generation systems on power quality. Energies 2016, 9, 739. [CrossRef]

13. Li, W.; Li, W.; He, X.; Xu, D.; Wu, B. General derivation law of nonisolated high-step-up interleaved converters with built-in transformer. IEEE Trans. Ind. Electron. 2012, 59, 1650-1661. [CrossRef]

14. Ajami, A.; Ardi, H.; Farakhor, A. A novel high step-up DC/DC converter based on integrating coupled inductor and switched-capacitor techniques for renewable energy applications. IEEE Trans. Power Electron. 2015, 30, 4255-4263. [CrossRef]

15. Yan, Z.; Ai-ming, S. Simplified ferrite core loss separation model for switched mode power converter. IET Power Electron. 2016, 9, 529-535. [CrossRef]

16. Yan, Z.; Qimi, C.; Junbo, Z. Predicting core losses under the DC bias based on the separation model. IEEE J. Emerg. Sel. Top. Power Electron. 2017, 5, 833-840. [CrossRef]

17. Han, Y.; Liu, Y.F. A practical transformer core loss measurement scheme for high-frequency power converter. IEEE Trans. Ind. Electron. 2008, 55, 941-948. [CrossRef]

18. Barg, S.; Ammous, K.; Mejbri, H.; Ammous, A. An improved empirical formulation for magnetic core losses estimation under nonsinusoidal induction. IEEE Trans. Power Electron. 2017, 32, 2146-2154. [CrossRef]

19. Steinmetz, C.P. On the law of hysteresis. Proc. IEEE 1984, 72, 196-221. [CrossRef] 